\title{
Estimation of odor emission rate from landfill areas using the sniffing team method
}

\author{
J. Nicolas, F. Craffe, A.C. Romain \\ Research Group "Environmental Monitoring", Department "Environmental Sciences and Management", University of Liège, Avenue de \\ Longwy, 185, B 6700 Arlon, Belgium
}

\begin{abstract}
The monitoring of the odor annoyance generated by a landfill area is difficult, since it is a multi-area-sources problem, with a discontinuous odor emission. This paper proposes an adaptation of the method of sniffing team campaigns to the particular case of fresh waste odors. The method is based on the field determination of odor perception points, followed by data processing with a bi-Gaussian-type model, adapted to handle the odors. In a first step, field observers delineate the region in which odor impact is experienced and then the emission rate is manipulated in a dispersion model until the predicted size of the impact zone matches that observed in the field. In a second step the adjusted emission rate is entered into the model to calculate the percentiles corresponding to the average annoyance zone. The originality of the proposed method is the introduction of all points and of all recorded meteorological data into the model. The paper discusses the method limitations and the errors induced on the results, i.e. the odor emission rate and the percentile lines (or iso-concentration lines) which are used to describe the odor concentrations on a map of the surroundings of the plant.
\end{abstract}

The proposed method proves to be reliable for diffuse sources, such as landfill areas. The obtained results are coherent with other results found in the literature with other techniques.

\section{Introduction}

Unpleasant smells can cause serious nuisance in the vicinity of sanitary landfills. Odors of different kinds are released by the fresh deposits of municipal solid waste, by the landfill gas (LFG), by the leachate treatment plants, by flares and by some waste treatment works, like composting facilities. Concerning solely the waste odor, there is a wide variety of emission sources, conveniently separated into the specific activities that liberate odorous compounds (Karnik and Parry, 2001) such as the active tipping of waste itself, but also the waste transportation by disposal trucks, the intermediate storage or the handling process after the garbage deposit.

Consequently, controlling odors from landfill sites has become an important regulatory issue, requiring accurate and reproducible sampling and measurement (Bradley et al., 2001).

But the monitoring of the odor annoyance generated by a landfill area is difficult. Problems appear already at the sampling level.

The most important sources at landfill sites are indeed passive area sources that are remarkably large (Frechen, 1995). Very often, it is not possible to sample more than $1 \%$ of the total area, so one must assume that the distribution of the specific emission rate is homogeneous, which is not realistic. Hamideh (2002) mentions more particularly the problem of sampling the landfill gas, which can provide compositional data that may be significantly different from the composition really emitted into the atmosphere.

Many authors mention also that the main odor problem of a landfill is caused by the handling of the fresh waste (Karnik and Parry, 2001; Stretch et al, 2001). As this is an intermittent activity, the sampling of the gas that is emitted at the landfill working face is particularly problematic.

Some additional problems arise at the analysis level.

Among the possible instrumental ways to assess the odor, the analysis of the ambient air by gas chromatography and mass spectrometry (GC-MS) can provide the concentration of the compounds of the odorous mixture 
(Gendebien et al., 1992; Bertacchi et al., 1997; Termonia and Termonia, 1999; Bradley et al., 2001; Bowly, 2003). Nevertheless, GC-MS cannot be considered as the appropriate procedure for field investigation owing to the low concentration of many odorous compounds in the environment and the lack of appropriate enrichment techniques. Moreover, it is not suitable in order to provide directly the global olfactive perception. When using the GC-sniffing method (with an odor port at the end of the GC column), no individual compound actually provides the typical and unpleasant smell of the fresh waste (Bradley et al., 2001). Moreover, such analytical instruments are often bulky laboratory systems.

Recently, some attempts were made to use the electronic nose for the field monitoring of the landfill odor (Nicolas et al., 2000; Pardo et al., 2001). Such technique leads to very promising results at the research stage, while its routine use to monitor on-site odor remains challenging. It notably entails the improvement of the quality of the used sensors: limit of detection, drift, influence of water content, etc.

For the above mentioned reasons, one of the most representative and the most frequently used way to assess the overall odor level still remains the sensory measurement using a panel of judges. Usually, the measurement goal is the determination of the mean odor emission rate from the whole landfill area, expressed in odor unit per second $\left(\mathrm{ou}_{\mathrm{E}} / \mathrm{s}\right.$ : the "E" stands for "European", as defined by the European standard EN13725 (2003), later on, this subscript will be used only if that European standard method is applied). Such outcome can be used for further evaluation of odor concentration percentiles prevailing for typical climatic conditions. That long term exposure is quantified in terms of a frequency of occurrence of hourly averaged concentrations above a certain limit odor concentration.

For example, the 98-percentile for a given odor concentration, e.g. $5 \mathrm{ou}_{\mathrm{E}} / \mathrm{m}^{3}$ (odor unit per cubic metre), represents the contour line delimiting the zone at the ground level where that concentration is exceeded more than $2 \%$ in the year. In short notation: $\mathrm{C} 98,1 \mathrm{~h}=5 \mathrm{ou}_{\mathrm{E}} / \mathrm{m}^{3}$. Here, "1 h" means that the concentrations are hourly averaged. This measure of exposure is calculated from the estimated or measured odor emission rate from the source, using an atmospheric dispersion model.

Knowing that $1 \mathrm{ou}_{\mathrm{E}} / \mathrm{m}^{3}$ corresponds to the odor detection threshold, in particular, the $\mathrm{C} 98,1 \mathrm{~h}=1 \mathrm{ou}_{\mathrm{E}} / \mathrm{m}^{3}$ percentile shows the limit of the area beyond which the odor is perceived less frequently than $2 \%$ of the time.

A first way to estimate the overall odor emission rate from a diffuse source, like the fresh deposits of municipal

waste, is to use an isolation flux chamber (Reinhart et al., 1992) or a portable wind tunnel (Jiang and Kaye, 1996) placed on the landfill surface to collect gases, which are then transferred to a Tedlar ${ }^{\circledR}$ bag for subsequent testing by olfactometry. Dynamic olfactometry (e.g. European standard EN 13725) is the method by which different dilutions of the gas sample are dynamically presented to trained odor assessors to determine the odor concentration of the original sample (in $\mathrm{ou}_{\mathrm{E}} / \mathrm{m}^{3}$ ).

The combination of surface sample collection and olfactometry provide both the concentration of odor (in ou $/$ $\mathrm{m}^{3}$ ) and the volume air flow (in $\mathrm{m}^{3} / \mathrm{s}$ ), the product of which is the specific odor emission rate (in $\mathrm{ou}_{\mathrm{E}} / \mathrm{s}$ ).

However, as already mentioned, such point samplings over the large and heterogeneous area of the landfill site pose the problem of the representativeness of the resulting emission rate. Moreover, it is impossible to estimate the flux of the odor emitted when handling the solid waste, or the one generated by the waste truck traffic by this method. Hence, the result provided by the method is only a part of the total odor emission rate.

Alternatively, the determination of the odor emission rate can be based on global field measurement, taking account of the real perception of the odor in the environment in the surroundings of the source. A possible approach is the method of the sniffing team observations, which utilises experienced people to evaluate the maximum distance from the source at which the odor is perceived. "Experienced people" means operators with reliable olfactory performance who always apply the same sniffing procedure. The results of a dozen of such measurements allow calculation of the typical odor emission rate with a dispersion model (Van Langenhove and Van Broeck, 2001). Sniffing team methods have some advantages over instrumental and olfactometric measurements. The main advantage is that they involve field measurements, by which the global impact of the source is evaluated, allowing consideration of diffuse, surface and less clear sources, such as waste handling or transportation. Furthermore, these methods reflect the actual perceptibility of the odor in the environment.

However, the sniffing team observation method also presents many limitations. That is chiefly the aim of this paper to describe them in detail. Firstly, it makes fundamental assumptions: it is valid only if both the 
meteorological situation and the odor emission do not vary too much during the measurement period. The waste odor around a landfill site is actually emitted as discontinuous puffs, depending on the activities on the landfill tipping face. Moreover, often accessibility problems in the surroundings of the site do not allow very quick observations. If the measurement takes about $1 \mathrm{~h}$, both the meteorological conditions and the emission rate can vary significantly.

The present paper discusses the applicability of the sniffing team observation method to estimate the annoyance zone around landfill areas. It is based on 52 measurements made on five different municipal solid waste landfill sites in

Wallonia, in the South of Belgium. The causes of the estimation bias are identified and the relative errors are estimated by a sensitivity analysis. The main topic of the paper is the discussion of the applicability of the methodology to diffuse and discontinuous odor sources. The results are only supplied for illustration purposes.

\section{Methods and case studies}

\subsection{Sniffing team method}

The sniffing method, as applied by the Department of Organic Chemistry at the University of Gent, is described in detail in Van Langenhove and Van Broeck (2001). One or two observers are firstly familiarised with the odor emitted by the source. If necessary, the olfaction performance of new and unexperienced observers may be checked against $n$-butanol, considered as a standard reference odor-ant, like for dynamic olfactometry (Van Harreveld and Heeres, 1995).

Then, they detect the odor at different points, by a zigzag movement around the axis of the plume. The transitional stages from no odor perception to odor perception are recorded on a detailed map, so that the odor area can be plotted and the maximum odor perception distance can be determined. By definition, the odor concentration at this maximum is $1 \mathrm{ou} / \mathrm{m}^{3}$. Strictly, this definition is only valid when the rigorous procedure of olfactometry, according to EN13725 standard, is respected. The detection threshold may be different in the environment than in laboratory conditions. However, we will consider that $1 \mathrm{ou} / \mathrm{m}^{3}$ corresponds also to the perception threshold for the present method. To avoid any confusion, we will not use the "E" subscript of $\mathrm{ou}_{\mathrm{E}} / \mathrm{m}^{3}$, valid only for the European standard method. The use of that unit is further examined in Section 4.

As the size of the odor perception area also depends on the meteorological situation at the time of the measurement, the wind direction, the wind speed and the solar radiation (or cloudiness) are simultaneously recorded. The two last parameters allow determination of the atmospheric stability using the Pasquill stability class system (Pasquill, 1974).

Then, a bi-Gaussian model, adapted to simulate the odor perception, is used with the average values of these meteorological data. The emission rate entered into the model is adjusted until the simulated average isopleth for $1 \mathrm{ou} / \mathrm{m}^{3}$ at about $2 \mathrm{~m}$ height (the height of the human nose) fits the measured maximum perception distance.

During that first step of the procedure, the model is thus considered only as a measurement tool to back-calculate the short term odor emission rate. The latter is used as a best-fit parameter for correlating predicted and observed impacts at various spatial locations around the odor source. At least 8 or 10 measurements per source are performed in order to take account of possible seasonal and meteorological influences and emission variability. The more different the stability classes, the wind direction and the wind speed are for the various measurements, the more representative will be the average result.

During the second step, the mean value of the emission rate over the measurement campaign is chosen as the typical emission rate for the studied site. It is further used to extrapolate the simulation by the same bi-gaussian model to a typical reference year and to calculate the percentiles allowing the assessment of a long term dispersion plume, which can be used to delineate an annoyance zone.

\subsection{Operating conditions}

The sniffing team method was applied to five landfill areas in Wallonia (South of Belgium), which is a region characterised by quite homogeneous climatic conditions, with prevailing wind directions NE and SW. Landfill sites (Mont-Saint-Guibert, Hallembaye, Champ-de-Beaumont, Cour-au-Bois, and Froidchapelle) are different in size (capacity from 0.8 to 5.3 million $\mathrm{m}^{3}$ ), in topography (from almost flat environment to slight hills) and in 
neighbourhood (always in rural areas, but from almost none to about 500 dwellings in a circular zone of $1 \mathrm{~km}$ radius around the active tipping area). Typically $100,000 \mathrm{~m}^{3}$ of waste are deposited per year on the landfill areas. All of the landfill sites predominantly receive municipal solid waste, which is immediately spread and compacted with suitable engines. There are no other odor sources in the immediate surroundings of the studied sites, except in the case of Hallembaye where the odor emissions of a hen house cannot, however, be confused with those of the fresh waste from the landfill.

Observers were trained by the same person prior to measurement campaigns, in order to be sure that all of them use the same procedure: detecting the same odor quality, considering the same minimum puff duration before acknowledging an odor point, staying about the same duration at each location, etc.

Odor measurements were carried out in the middle of the day, between 10 and 14 o'clock, when the fresh garbage was not covered by a capping yet. A deodorising system is available on almost all of the landfill sites, but the atomisa-tion of the masking or the neutralising agent was always stopped at least half an hour before the beginning of the measurement.

About 10 measurements were carried out on each landfill site, with a total of 52 measurements, at different periods of the year. Each campaign for a given site was conducted during a period of 1 or 2 months. The study was made in the frame of a follow-up monitoring of all landfill sites in Wallonia, initiated by the Ministry of Environment. The typical duration of a sniffing field inspection was from 20 to $60 \mathrm{~min}$. Each time, a portable meteorological station was placed on an elevated place, close to the tipping area, and wind speed, wind direction, solar radiation and temperature were recorded 2 times per min. For each observation, the stability class was deduced from the Pasquill table. The information about the height of the inversion layer was not available and therefore was not used.

Data was processed using the TROPOS model (Odo-tech, Canada). It implements a bi-Gaussian formula, with suitable corrections to handle odor. It is well known, however, that for dispersion modelling of odors, the Gaussian model is inappropriate because it gives only hourly averaged concentrations, whilst the human response time for the detection of odor is typically of the order of $1 \mathrm{~s}$. This suggests that accurate odor prediction could require resolution of concentration fluctuations on time scales of about 1 s (Pagé and Guy, 1997; Stretch et al., 2001).

Some corrections can be applied to the Gaussian model in order to reflect the annoyance generated by concentration peaks (Turner, 1994). TROPOS implements the meandering model of Gifford (1959), superposed to the Gaussian plume. The idea is to consider an instantaneous plume that meanders between the limit of Gaussian boundaries. By combining the Gifford model to the Gaussian model, it is possible to take account of both the evolution of the concentration fluctuations and the resulting homogeneous plume (Pagé and Guy, 1997).

Finally, the percentiles were calculated for average climatic conditions available for the closest synoptic station of the Belgian Royal Meteorological Institute (BRMI). The meteorological file was deduced from a publication of BRMI (Van der Auwera, 1991) where frequencies of occurrence were calculated for each combination (wind speed class/wind direction sector/stability class) for 22 synoptic stations in Belgium, on the basis of about 40 years of hourly observations. To respect the TROPOS requirements for the input data format, each of those meteorological combination is repeated as separate input records, as many times as its occurrence in the BRMI file.

\subsection{Specific approach}

If the sniffing team method were applied as described above, with only one mean meteorological observation for the measurement period and only the maximum perception distance, the deduced emission rate of landfill sites may be underestimated. The intermittent character of the landfills odor emission and the variation of the wind speed and direction during the measurement period are actually not taken into account by an average $1 \mathrm{~h}$ observation.

Consequently, we adapted the method to work with such fugitive emissions and such difficult access sites.

Firstly, during the walk around the site, points where the odor is perceived are noted on the map. When the observer sniffs only a puff, he passes a second or even a third time to confirm his perception. A total of about 20 measurement locations are investigated in this way, by exploring particularly the zone where the odor vanishes. At each location, the observer sniffs during 1 or $2 \mathrm{~min}$, and he notes if an odor is perceived or not. 
Then, all the recorded meteorological data is entered into the dispersion model, not only the average ones.

That manner of using the model is explained in detail in Section 4.

The procedure consists then in adjusting the emission rate by trial and error so that the $1 \mathrm{ou} / \mathrm{m}^{3}$ isopleth surrounds at best all of the "odor" points on the map. Although the method is adapted to the variations of the wind direction, measurements are discarded when the wind direction is too variable.

\section{Typical results}

Although the landfill gas (LFG) odor was sometimes perceived on some sites, the sniffing concerned exclusively the fresh garbage odor, which was, by far, the strongest odor during activity periods and which generally corresponded to the complaints in the surrounding area. LFG emissions are actually due to imperfectly airtight extraction wells. For all of the investigated sites, LFG collection networks are very efficient and LFG odor was exceptional and only locally detected. However, that shows the importance of the familiarisation of the observers with the typical smell of the source. In our case, many different odor characters could locally be perceived on the same site: the sour smell of the fresh waste, or the sickly sweet smell of the LFG, or the "rotten-egg" odor of leachates, or in some cases, the odor of the compost used as capping material or the one of sewage sludge temporarily stored on the site. After a short training, the observer can easily distinguish all of the odor qualities.

Fig. 1 shows a typical $1 \mathrm{ou} / \mathrm{m}^{3}$ isopleth estimated by the TROPOS model and including "at best" the "odor" points as identified in the field at Froidchapelle. The details of the meteorological conditions are given on the figure. The standard deviation (sd) of the wind direction is calculated by the Yamartino method (Yamartino, 1984). The stability class is estimated according to the Pasquill scheme. The measurement took about $40 \mathrm{~min}$ during which five trucks tipped waste on the working area represented at the bottom-left by a shaded polygon. The arrow indicates North. Black circles are the "odor" points and crosses are some "no-odor" points (only those which are close to the limit are drawn).

Fig. $1.1 \mathrm{ou} / \mathrm{m}^{3}$ Isopleth as estimated by the TROPOS model for Froidchapelle landfill and including at best the odor points identified in the field (black circle) and not the points where the odor is not perceived (cross).

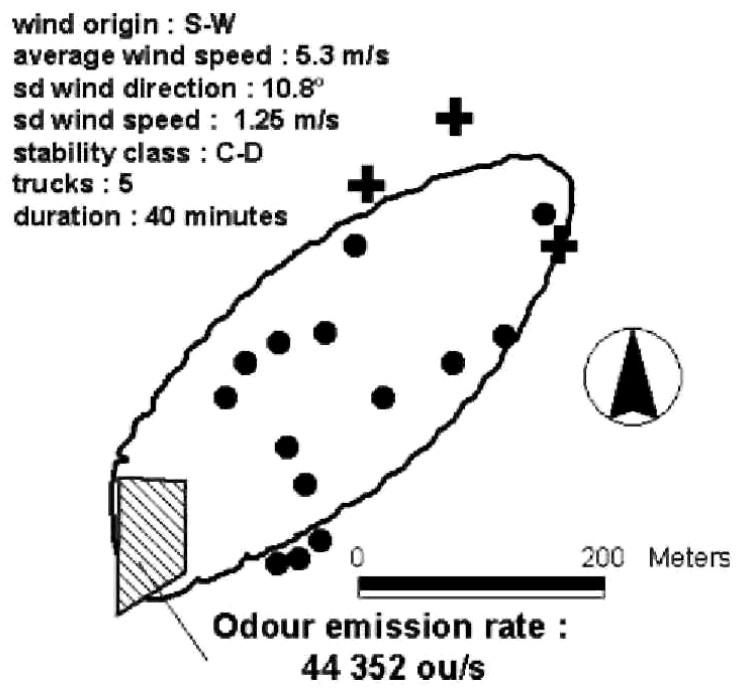

The maximum distance of odor perception in the wind direction is about $450 \mathrm{~m}$ from the centre of the tipping area. By trial and error, using the TROPOS model, we adjusted an odor emission rate of 44,352 ou/s to surround nearly all the "odor" points and avoid the "no-odor" points. Here, the 80 meteorological observations recorded every $30 \mathrm{~s}$ during the $40 \mathrm{~min}$ sniffing period are entered into the model, leading to plume shape and size corresponding well to the observed one. In this case, entering only the average values of the climatic parameters for the whole measurement period should produce about the same adjusted emission rate and similar plume shape. 
Fig. 2 shows a different case, for the landfill of Champ-de-Beaumont. In this case, the measurement took 85 min, because the access to the surrounding area was more difficult than at Froidchapelle. The climatic conditions were also more changing than the previous ones: overcast sky, standard deviation of the wind direction $30.4^{\circ}$. On the figure, the continuous line represents the $1 \mathrm{ou} / \mathrm{m}^{3}$ isopleth adjusted with all of the 170 meteorological observations, and the dotted line represents the $1 \mathrm{ou} / \mathrm{m}^{3}$ isopleth for only the average value of meteorological parameters, leading to the same maximum distance in the wind direction. Now, the shape of the two isopleths are quite different and the adjusted emission rate for the average condition is about half the one adjusted for all the observations.

Other isopleths adjusted from the 52 measurements lead to various shapes between these two extremes. Using all of the meteorological observations and considering all of the investigated sites, the deduced emission rates are in the range $(8750,137,500 \mathrm{ou} / \mathrm{s})$. As mentioned before, this typical emission rate results both from the diffuse odor emitted by fresh garbage deposited on the working face (area source) and from the waste handling and transportation. Anyway, by dividing each emission rate by the estimated surface of the tipping area for each landfill site (i.e. from 1500 to $5000 \mathrm{~m}^{2}$ ), an equivalent emission flux can be assessed: between 8 and $30 \mathrm{ou} / \mathrm{m}^{2} \mathrm{~s}$.

Fig. $2.1 \mathrm{ou} / \mathrm{m}^{3}$ Isopleth as estimated by the TROPOS model for Champ-de-Beaumont landfill. Black circles indicate "odor" points and crosses indicate "no-odor points". Dotted line isopleth corresponds to the average meteorological observation.

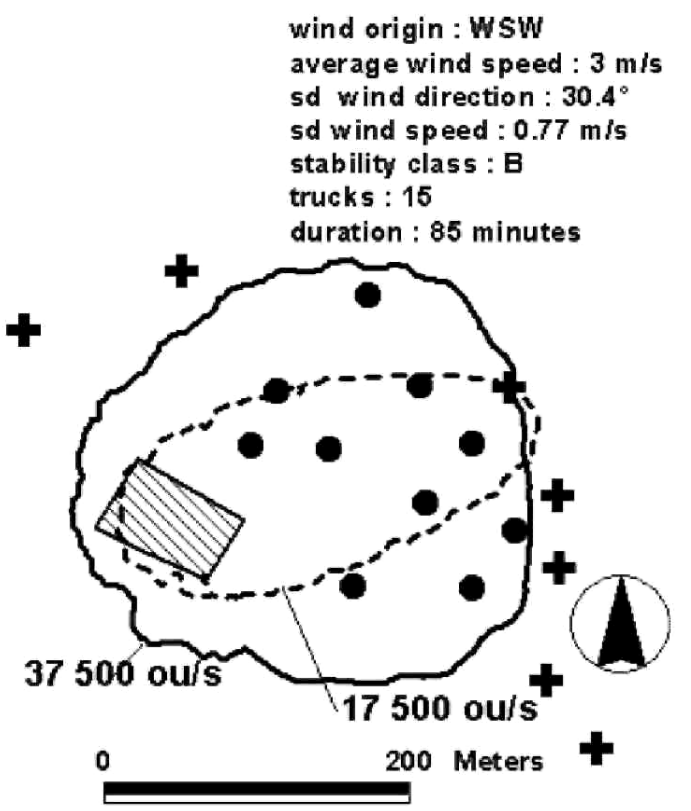

The maximum distance of perception varies from 230 to $810 \mathrm{~m}$, with an average value of $425 \mathrm{~m}$. The adjusted emission rate is poorly correlated with the number of trucks arriving at the landfill site during the sniffing period (coefficient of correlation from -0.11 to 0.54 for all of the measurement campaigns). That proves that the odor depends on other factors and not only on the freshly tipped waste volume. We observed that the handling effort of fresh waste often was the most important cause of odor releasing.

With the adjusted emission rates, the dispersion model calculated percentiles of 95, 98 and 99.5 corresponding to the limit of perception of $1 \mathrm{ou} / \mathrm{m}^{3}$ for the typical climate of the region, on an hourly basis. The resulting area for percentile $98\left(\mathrm{C} 98,1 \mathrm{~h}=1 \mathrm{ou} / \mathrm{m}^{3}\right)$ is a kind of ellipse with a major axis of 1200-3000 m oriented along the prevailing wind direction and with a minor axis of about 800-2100 m. Fig. 3 shows such typical percentile which can be drawn on a digitalised site map in the background. The figure is just an example and illustrates the "Champ-de-Beaumont" landfill. If the buildings are highlighted on such graphical view, it is possible to count the number of residents who are potentially annoyed by the odor. In our studies, we considered this area as the odor nuisance zone. 


\section{Discussion of the method}

\subsection{Method validation}

The estimated emission fluxes are coherent with other results found in the literature. Karnik and Parry (2001) cite different measurement exercises, ((Frechen, 1995) and a study of OdourNet UK Ltd in association with Biffa Ltd). The combined results show that the process of waste deposition leads to odor emissions in the range of 60 $\mathrm{ou} / \mathrm{m}^{2} \mathrm{~s}$, which decrease to values between 1 and $25 \mathrm{ou} / \mathrm{m}^{2} \mathrm{~s}$ for areas of uncovered waste where disposal has ceased. Odotech Inc., Canada (Odotech, 2001), measured the odorous emissions on a Canadian landfill site and values of 2.6, 5.4 and $3.5 \mathrm{ou} / \mathrm{m}^{2} \mathrm{~s}$ were found for old waste, for mixed waste, and for the truck waiting area, respectively. Odor emission rates quite lower than ours are measured by all authors using an isolation flux chamber to collect specific samples on the waste at rest. Bowly (2003) finds $0.3-0.5 \mathrm{ou} / \mathrm{m}^{2} \mathrm{~s}$ and Sironi et al. (2003) measure $2 \mathrm{ou} / \mathrm{m}^{2} \mathrm{~s}$ for freshly tipped waste and $4.5 \mathrm{ou} / \mathrm{m}^{2} \mathrm{~s}$ for freshly tipped sludge during summer. Concerning the overall emission rate, a study conducted by Certech asb1 (Belgium) on one of the five landfill sites presented here (Mont-Saint-Guibert) leads to a value of about 34,000 ou/s for the total emission rate from all area sources of fresh waste odor, using rather heavy sampling (isolation flux chamber, carrier gas cylinder, Tedlar $^{\circledR}$ bags, for about 10 sampling locations) and olfactometric measurements. For the same site, we found $30,146 \mathrm{ou} / \mathrm{s}$.

Fig. 3. Typical percentile 98 for $1 \mathrm{ou} / \mathrm{m}^{3}$ resulting from TROPOS simulation with average climatic conditions and illustrating the "Champ-de-Beaumont" landfill site.

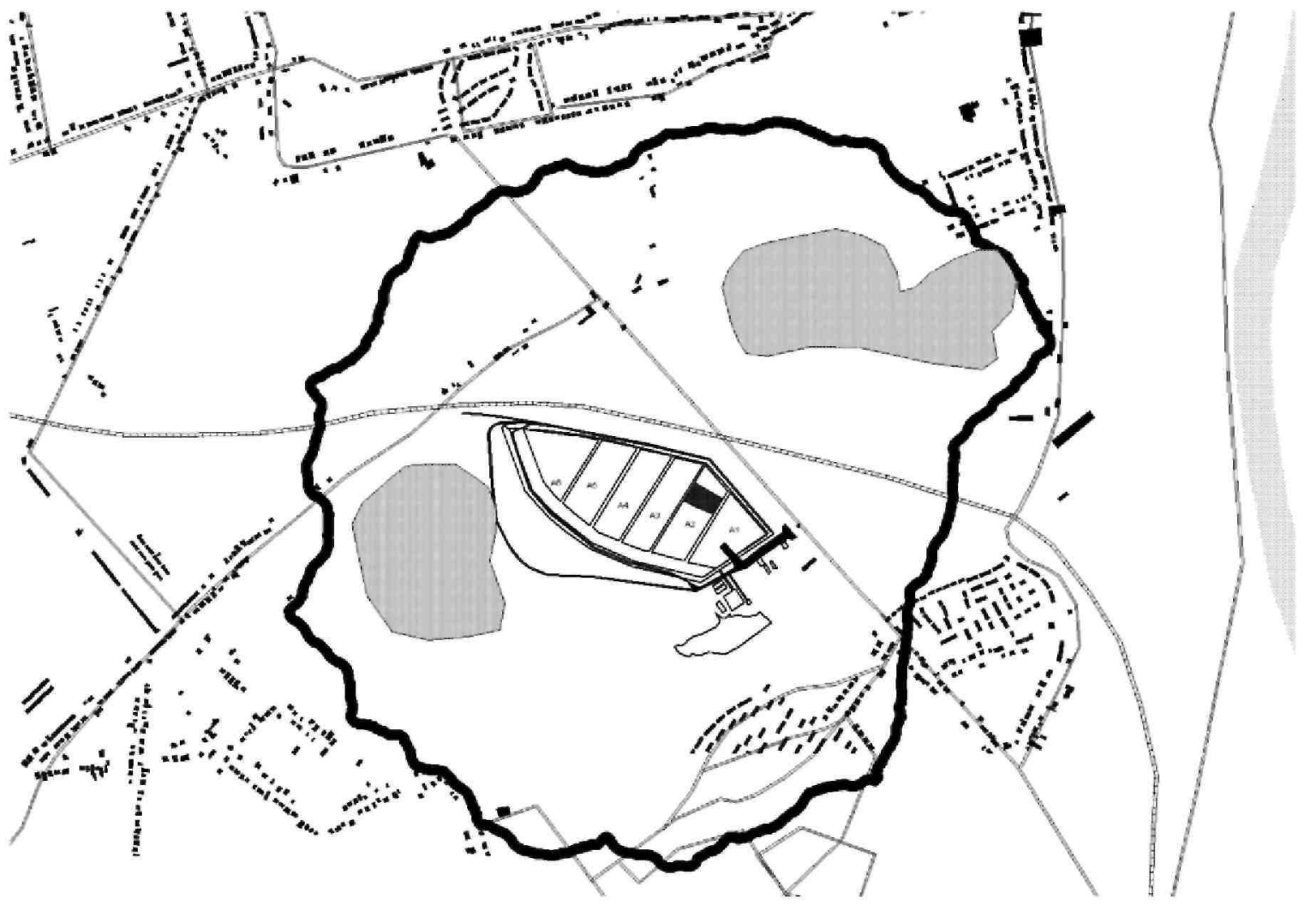

Another way of assessing the robustness of the method is to verify that the annoyance zone, as defined by the percentile 98, actually corresponds to the area where complaints are recorded. For the five sites, the location of the complainant houses are indeed always inside the zone defined by the percentile. At Cour-au-Bois such verification is based on about 2000 observations made by the residents and by the landfill staff. Particularly, one observer, living at about $500 \mathrm{~m}$ from the tipping area, regularly noted his perception. After 1 year, he smelled the odor of fresh garbage $18 \%$ of time. From our estimation, the percentile running through his house is C85 (for 1 $\mathrm{ou} / \mathrm{m}^{3}$ ), corresponding to a waste odor perceived during $15 \%$ of time. The agreement between both percentages is good, but it can only be considered as a first indication since the odor observations made by the resident are not continuous. At least, it is concerned about the same odor emission as the one we have measured, because the 
observer sniffed only at precise hours during the landfill activity period.

No further validation can be made with the collected data set itself. For the same facility, the emission rate varies from day to day, so that a given adjusted emission rate cannot be used to check the predictive ability of the model for another day.

Therefore, the continuation of the discussion part does not go deeper in the processing of the above presented data but it essentially discusses the limitations of the applied method. It identifies and quantifies the various error sources and suggests optimal use of the sniffing team method for landfill odors.

\subsection{Influence of the human sensitive perception}

A first cause of error is connected to the subjective character of the human nose perception of the odor. Moreover, for reasons of availability of persons of the research staff, the sniffing "team" was often reduced to two observers, and sometimes to only one. So, while employing trained operators, the used method did not fulfil all the requirements of the German or Dutch guidelines describing odor measurements with smelling squads (VDI, 1993; Anzion et al., 1994). That could make the obtained results questionable.

The research group ENVOC, from Gent University in Belgium experienced the sniffing team observation method in a very great number of different cases and they conclude that one single observer is sufficient since the difference in observed maximum perception distance for different observers is only 10-15\% (Moortgat et al., 1992; Van Langenhove and Van Broeck, 2001). Our research confirms such values: we investigated a similar method with student teams in different cases, comparable to the one of landfill site, and the range of the estimated values of the maximum perception distance among all the observers was always within $10 \%$.

On the basis of the 52 studied cases concerning landfill sites, such error in the maximum perception distance gives rise to an error of $20-30 \%$ on the estimation of the odor emission rate, as adjusted by the model. Such an error generates in turn an error of $13-20 \%$ on the extent of the percentiles calculated with the typical meteorological conditions.

\subsection{Error in the estimation of the stability class}

The stability class (from A to F, according to the Pasquill scheme) is one of the parameters to which the model is the most sensitive. The present study bases the stability assessment on the wind speed and solar radiation measurements as well as on the personal cloudiness estimation of the observer.

Assuming that we can mistake two adjacent stability classes, the error generated on the adjusted odor emission rate should be about $30 \%$, inducing an error of $20 \%$ on the percentile size. However, with the methodology recommended in the present study, every meteorological observation is entered as input data in the model. As a stability class is estimated for each observation, we may expect that the errors of estimation will complement each other when adjusting the overall odor emission rate, and so the error in the result should nearly vanish.

\subsection{Influence of the choice of the model}

Besides errors ascribable to measurement, there exist, upstream from the study, errors due to the choice of the model type and to the one of the computer code.

First of all, we may question the choice of a bi-Gaussian-like model, neglecting the topography and the dynamics of pollutant transport, for reasons of easiness and of information availability. It is very difficult to estimate the error due to this choice, because another choice should not necessarily constitutes a more reliable reference. For example, a numerical Eulerian-model, implementing the equations of the fluid dynamics, allows taking of the topography into account, but it requires the knowledge of a great number of parameters whose estimation is also subject to errors.

Our personal experience shows that the bi-Gaussian model is sufficient for a rather flat terrain and for a raw estimation of the odor emission rate (at 20-30\%) that cannot be measured by a direct method.

Nevertheless, it is well known that the effect of complex terrain is a factor complicating the prediction of odor dispersion in the specific case of landfills (Stretch et al., 2001). Many landfills are deliberately situated in deep valleys for practical and aesthetic reasons. Hilly terrain can affect the local turbulence and consequently the 
mixing and the odor dilution, but few models are able to handle such complex terrains.

A brief study carried out for the site of Champ-de-Beaumont with the Eulerian 3D-model IBSUrban (Germany) seems to show that the relief influence is chiefly marked in the immediate surroundings of obstacles, but it does not modify considerably the size and the shape of the calculated percentile.

An additional error can be induced by the choice of the specific algorithm used in the model to simulate specifically the odor dispersion. Turner (1994) proposed a peak-to-mean ratio which can be used as a correction factor to modify the averaging time of the concentration. Some computer codes propose simply a factor 10 correction (i.e. the odor concentration is 10 times the gas concentration calculated by the classical Gaussian model). TROPOS uses a meandering model combined with the Gaussian one.

With respect to such coupling of the algorithms, the pure Gaussian approach leads to an adjusted odor emission rate $52 \pm 4 \%$ higher for our 52 measurements.

The differences in the adjusted emission rates induced by the correction algorithms are rather important, but, in terms of averaged percentile, the differences between models lessen when the same model is used both to adjust the emission rate and to calculate the percentile for the typical climate of the region. That is an important outcome for such a method: as long as the intermediate result, i.e. the odor emission rate, is not exploited, the choice of the model is not really restricting for the estimation of the average annoyance zone.

\subsection{Influence of the frequency of the meteorological observations introduced into the model}

The choice of the model is important, but the way of using it is essential and can lead to significant errors of estimation of the odor emission rate and of the corresponding percentiles. As stated before, the sniffing team method is based on hourly averaged meteorological observations, as the Gaussian-type models are valid for averaging times of 10-60 min. We propose here to introduce all of the meteorological observations, recorded with a frequency of one every $30 \mathrm{~s}$. This manner of applying the Gaussian-type model is questionable. In particular, the stability class is a notion having an "inertia" and its effect on the odor dispersion does not change two times a minute. However, as shown in Fig. 2, the $1 \mathrm{ou} / \mathrm{m}^{3}$ isopleth calculated with all of the meteorological observations seems more realistic than the hourly averaged one, with respect to field observations. Introducing all of the available meteorological observations actually leads to less sharp isopleths.

Using only hourly averaged meteorological observations presents indeed some drawbacks.

- If the main wind direction is not correctly identified by the observers at the beginning of their walk, they can go in a wrong direction and indicate a maximum distance that is not in the main wind direction.

- For measurement duration of 40-80 min, this maximum perception spot fluctuates with time and it is not always possible to reach it before the wind direction changes.

- The bi-Gaussian model is very sensitive to variations of the stability class. If the actual estimated average stability class is between $\mathrm{C}$ and $\mathrm{D}$, as the model does not accept intermediate classes, the choice of either C or D can generate a significant bias.

Introducing into the model all of the meteorological observations, as well as all the "odor" spots, avoids these problems. Taking account of all of the wind directions, all of the wind speeds and all of the stability classes really observed during the measurement is more realistic. That results in averaging the final result of the model instead of averaging the input data, and particularly to really average the effect of the stability class.

Using only one mean meteorological observation in place of all resulted in reduction of the adjusted emission rate by $47 \pm 17 \%$ on average on the 52 studied cases. Of course, this reduction should vanish if all of the observations were similar during the measurement period, but it should tend to increase with the fluctuations of the meteorological parameters. That general trend is illustrated in Fig. 4 where the reduction of the emission rate (in $\%$ ) is plotted against the standard deviation of the wind direction for the 52 cases.

\subsection{Influence of the choice of the isopleth identified to the perception limit}

In the present study, we have adjusted the odor emission rate so that the $1 \mathrm{ou} / \mathrm{m}^{3}$ isopleth surrounds about all of the "odor" points identified in the field. We have thus considered that the "odor" spot at the maximum distance from the source corresponds to the odor perception threshold. We could consider another isopleth, such as the one corresponding to $3 \mathrm{ou} / \mathrm{m}^{3}$, known to be the recognition threshold. The observer in the field follows indeed only the studied odor, and thus, he has to recognise it. Alternatively, we could also consider the $5 \mathrm{ou} / \mathrm{m}^{3}$ isopleth, 
which is the annoyance threshold. Such alternative choices lead to very different adjusted odor emission rates: three times more important for example for the $3 \mathrm{ou} / \mathrm{m}^{3}$ isopleth with respect to the $1 \mathrm{ou} / \mathrm{m}^{3}$ one. That is really a tricky choice. A nice manner to dodge the issue is suggested by Van Lan-genhove and Van Broeck (2001) who do not use the odor unit per cubic metre but a personal "sniffing unit per cubic metre" $\left(\mathrm{su} / \mathrm{m}^{3}\right)$ to avoid confusion. The adjusted odor emission rate is then expressed in su/s and the calculated percentile corresponds to $\mathrm{su} / \mathrm{m}^{3}$. From a pure scientific point of view, such an approach is more accurate and irreproachable. The problem with our studies is that they are often carried out in the frame of the granting of exploitation licences for which the reference values for enforcement are expressed in odor units. The need to compare our results with some external references can justify the risk of expressing the results in odor units. As stated above, we will just avoid use of the "E" subscript of $\mathrm{ou}_{\mathrm{E}} / \mathrm{m}^{3}$ to explicitly mention that it is not the standard European method EN13725 that is applied. In all events, in so far as the main options are coherent from one measurement campaign to another, results can be used in a relative way to appraise the differences between various situations. As stated above, it is encouraging to note that the obtained odor emission fluxes from landfill areas are of the same order of magnitude as the ones obtained with other methods.

Fig. 4. Increase trend of the difference between the approach "individual observations" and "average climate" in function of the standard deviation of the wind direction for the 52 studied cases.

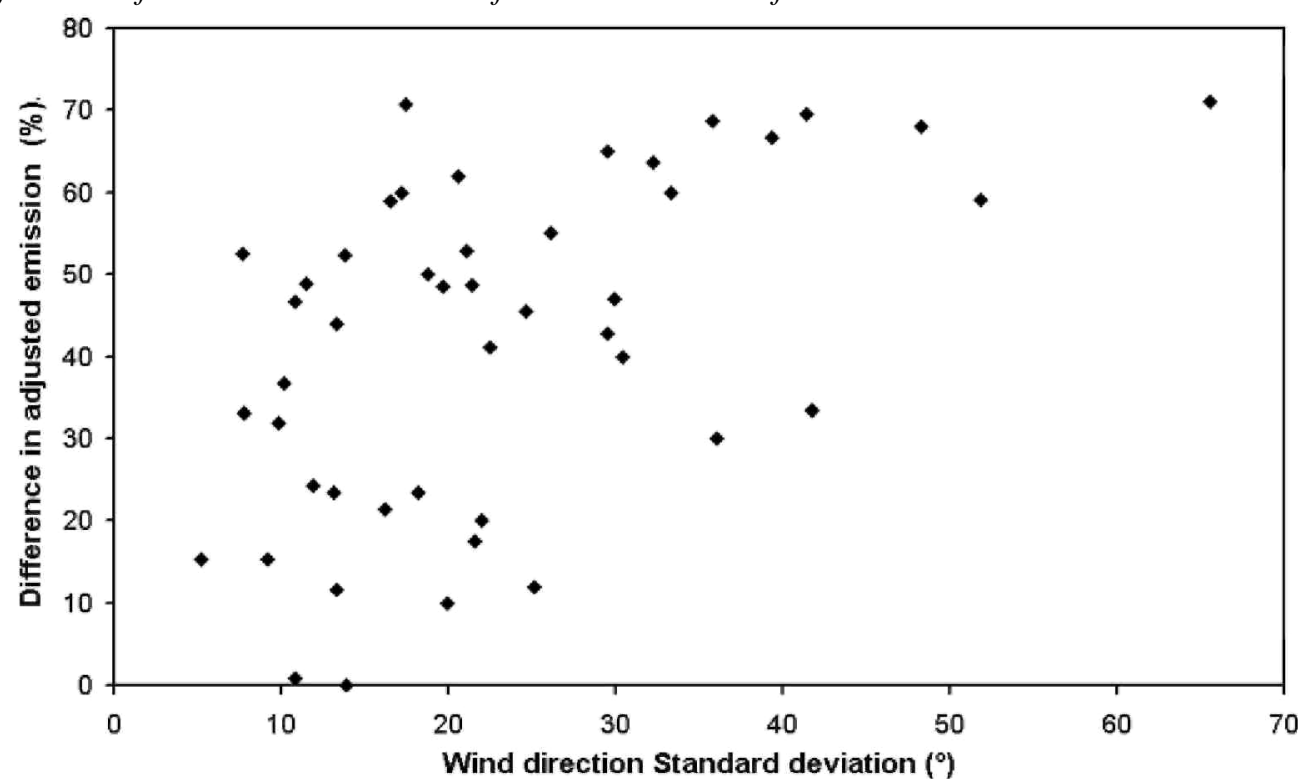

\subsection{Other influences}

Some other minor influences can be cited.

The used models always make the assumption that wind speed and direction are measured at $10 \mathrm{~m}$ above the ground level and far away from any obstacle. The field reality is sometimes a little bit different. Measurement is always carried out on an elevated point (in general on a hillock close to the tipping area), with a mast height of about $2.5 \mathrm{~m}$, so that the actual measurement height (hillock height + mast height) is not always exactly $10 \mathrm{~m}$.

The maximum error can be calculated for the worst case, when estimating a measurement height of $10 \mathrm{~m}$ whereas it actually was only $2.5 \mathrm{~m}$. Then the overestimation of the wind speed is about $25 \%$, which gives rise also to a systematic error of $25 \%$ on the adjusted odor emission rate. However, such false increase of the wind speed is concomitant with an overestimation of the air stability, which tends to lower the adjusted emission rate and thus compensates the effect of the sole wind speed. It can be estimated that the maximum residual error is less than $5 \%$.

The pollutant plume can progress upwards from the release height until the mixing height and downwards until the ground. The usual way to handle such limits in dispersion modelling is to consider that both boundaries act as mirrors and thus that the plume undergoes a total reflection on them. Neglecting the presence of a possible inversion layer does not affect the final result, since the influence of the inversion layer appears only for 
extremely low mixing heights, which were never observed during our measurements.

In the case of the odor generated by waste on a landfill area, the release height is generally estimated at $0 \mathrm{~m}$ and the plume rise, eventually due to building or buoyancy effects, is neglected. As the odor is actually released from a garbage heap, sometimes relatively elevated with respect to the surroundings, and as the emitted gases are sometimes at a temperature above ambience, such simplifications could also generate specific errors on the results. By modifying in the model the release height from 0 to $5 \mathrm{~m}$ and the emission temperature from 300 to $400 \mathrm{~K}$, no discernable difference was noted on the adjusted odor emission rate.

Dispersion models simulate a diffuse emission by a network of point sources, evenly distributed in a polygonal zone defined by the user. In the case of landfill sites, the active tipping area is not a well delimited zone. It is generally approximated by a rectangular zone (e.g. of $50 \mathrm{~m} \times 50 \mathrm{~m}$ ), whose length and width do not always point to the exact azimuth directions. By modifying the size of the diffuse emission zone from 900 to $3600 \mathrm{~m}^{2}$ and the type of polygonal shape (rectangle, square trapeze, triangle, etc.), the error generated on the emission rate was less than $1 \%$.

\subsection{Summary of the various errors}

Table 1 summarizes the various identified errors and their effect on the adjusted results, for the 52 studied cases on landfill areas. The sign and the relative value of the considered error are evaluated with respect to the choices of the present study: Gifford algorithm coupled with the bi-Gaussian model, no reflection on the mixing layer, etc. The first five errors represent the range of possible values inside the proposed methodology, i.e. estimation errors. The five remaining ones correspond to discrepancies with respect to the proposed methodology when other choices are made, i.e. methodological errors.

Table 1. Summary of the identified errors and of their effect on the adjusted results

\begin{tabular}{|c|c|c|c|c|}
\hline \multicolumn{2}{|c|}{ Cause of the error } & Error type & $\begin{array}{c}\text { Relative error of } \\
\text { the odor emission } \\
\text { rate }\end{array}$ & $\begin{array}{c}\text { Relative } \\
\text { error of the } \\
\text { percentile } \\
\end{array}$ \\
\hline \multirow[t]{5}{*}{ Estimation errors } & Field sensitive perception & Random, in both directions & \pm 10 to $\pm 15 \%$ & \pm 7 to $\pm 10 \%$ \\
\hline & $\begin{array}{l}\text { Height of measurement of } \\
\text { wind speed and direction }\end{array}$ & Systematic, over-estimation & $+5 \%$ & $+3 \%$ \\
\hline & Estimation of stability class & Random, in both directions & $<5 \%$ & $<3 \%$ \\
\hline & $\begin{array}{l}\text { Release height and plume } \\
\text { rise }\end{array}$ & $\begin{array}{l}\text { Systematic, under- } \\
\text { estimation }\end{array}$ & $<1 \%$ & $<1 \%$ \\
\hline & $\begin{array}{l}\text { Size and shape of the } \\
\text { diffuse emission }\end{array}$ & $\begin{array}{l}\text { Systematic, the direction } \\
\text { depends on the emission } \\
\text { zone }\end{array}$ & $<1 \%$ & $<1 \%$ \\
\hline \multirow[t]{5}{*}{$\begin{array}{l}\text { Methodological } \\
\text { errors }\end{array}$} & $\begin{array}{l}\text { Choice of a bi-Gaussian } \\
\text { model }\end{array}$ & $?$ & $?$ & $?$ \\
\hline & $\begin{array}{l}\text { Choice of an algorithm to } \\
\text { simulate the odor }\end{array}$ & $\begin{array}{l}\text { Systematic, the direction } \\
\text { depends on the algorithm }\end{array}$ & $-85 \%$ to $+52 \%$ & $-60 \%$ to $35 \%$ \\
\hline & $\begin{array}{l}\text { Frequency of } \\
\text { meteorological observations } \\
\text { entered into the model }\end{array}$ & $\begin{array}{l}\text { Systematic, under- } \\
\text { estimation if average } \\
\text { meteorological conditions } \\
\text { are considered }\end{array}$ & $-47 \%$ & $-31 \%$ \\
\hline & $\begin{array}{l}\text { Choice of the isopleth } \\
\text { identified to the perception } \\
\text { limit }\end{array}$ & $\begin{array}{l}\text { Systematic, the direction } \\
\text { depends on the chosen } \\
\text { isopleth }\end{array}$ & $-46 \%$ to $+300 \%$ & $\begin{array}{l}-30 \% \text { to } \\
+200 \%\end{array}$ \\
\hline & Reflection on mixing layer & $\begin{array}{l}\text { Systematic, under- } \\
\text { estimation }\end{array}$ & $<1 \%$ & $<1 \%$ \\
\hline
\end{tabular}




\section{Conclusions}

Among the above listed errors, those which are due to methodological options are by far the most important ones. It is clear that such a method, involving notably the use of a model, leads only to approximate measurement results since it is based on a crude representation of the reality. Such methodological errors must be pointed out to show the limits of the approach and to relativize the importance of the field observations. Nevertheless, they should not be considered in the calculation of a confidence interval around the estimated percentile. If all the methodological options are well argued, they define the exact frame of the used method and one must only care about the biases induced by deviations with respect to this reference method.

Those considerations do not prevent the method to be improved when it is possible. More particularly, a significant finding is that the Pasquill stability classes scheme does not offer a sufficiently fine resolution to be used in the Gaussian-type models (or a least in most computer codes) when a single hourly averaged meteorological observation is used to adjust an odor emission rate.

The validation of such a method is not easy: the emission is discontinuous and diffuse. The validation for all of the weather situations and various emission types should request substantial amount of work and money.

The results of other similar studies could be used for an attempt of validation of our own method, but few scientific papers or technical reports provide all the data required to apply the model. In the appendices of a study concerning livestock odors carried out by the University of Gent (De Bruyn et al., 2001), a table gives the maximum distance of odor perception, the average meteorological conditions prevailing during the measurement period and the odor emission rate as adjusted by the model. Applying the TRO-POS code on these data with the above mentioned hypothesis leads to adjusted emission rates nearly equivalent in average to the ones obtained by the group of Gent. Some point results deviate by about $45 \%$ from the original emission rate, but it is only observed for unstable atmosphere, because the processing of stability classes by the used model is not exactly the same as in TROPOS.

To sum up, we may conclude that the proposed method is proved reliable for the determination of percentiles of the odor perception threshold exceeding for typical climatic conditions. All errors induced on the final result, especially the methodological biases, are very reduced if the intermediate result, i.e. the odor emission rate, is not exploited as output variable and if the same model, with the same hypothesis, are used both to adjust the emission rate and to calculate the percentiles. Although the described method is particularly well adapted for perturbed climatic conditions and fluctuating odor emissions, its reliability is maximum for rather steady situation and when the detection of limit points is carried out as fast as possible.

\section{References}

Anzion, C.J.M., Dragt, A., van Kuijk, A.H.J., Post, J.G., 1994. Document meten en rekenen geur (Odor Measurement and Computation Document). Den Haag, Ministerie VROM.

Bertacchi, M., Capuano, F., Fornaciari, S., Franzoni, C., Poluzzi, V., Renna, E., Vvivi, B., Bertolini, E., Meglioli, E., 1997. Control of the air quality and research of smelling substances in landfills. Sardinia 1997, Cagliari, Italy.

Bowly, S.W., 2003. An assessment of current methods for quantifying landfill odours. Sardinia 2003, Cagliari, Italy.

Bradley, A.D., Cook, D.J., Edwards, J.S., Johnston, A.G., Linforth, R.S.T., Taylor, A.J., 2001. The control and measurement of landfill odours. Sardinia 2001, Cagliari, Italy.

De Bruyn, G., Baron, M., Van Langenhove, H., Hendriks, J., Andries, A., Saevels, P., Leribaux, C., Vranken, E., Vinckier, C., Berckmans, D., 2001. Ontwikkeling van een eenvoudige procedure voor de bepaling van geur- en ammoniakemissies van agrarische constructies ten behoeve van een aagepaste milieureglementering in Vlanderen. Deel 2: Meetprocedure voor ammoniak -en geuremissies van agrische constructies (Development of a simple procedure for the determination of odor and of ammonia emissions from farm buildings aiming at the adaptation of environmental policy in Flanders. Part 2. Measurement procedure for ammonia and odor emissions from farm buildings). Gent, KUL \& RUG, 166

EN13725:2003, Air Quality Determination of Odor Concentration by Dynamic Olfactometry, CEN, Brussels, April 2003. Available from: <www.cenorm.be>. 
Published in: Waste Management (2006), vol. 26, iss. 11, pp. 1259-1269

Status: Postprint (Author's version)

Gendebien, A., Pauwels, M., Constant, M., Ledrut-Damanet, M.J., Nyns, E.J., Willumsen, H.C., Butson, J., Fabry, R., Ferrero, G.L., 1992.

Landfill gas. From environment to energy. Luxembourg, Commission of European Communities.

Gifford, F.A., 1959. Statistical properties of a fluctuating plume dispersion model. Adv. Geophys. 6, 117-138.

Hamideh, S.A., 2002. A review of the literature regarding non-methane and volatile organic compounds in municipal solid waste landfill gas. MSW Manage. 12

Jiang, K., Kaye, R., 1996. Comparison study on portable wind tunnel system and isolation chamber for determination of VOC's from areal source. Water Sci. Technol. 34, 583-589.

Karnik, M., Parry, C., 2001. Landfill odour control - a practitioner's experience. Sardinia 2001, Cagliari, Italy.

Moortgat, M., Schamp, N., Van Langenhove, H., 1992. Assessment of odour nuisance problem in Flanders: a practical approach. In: Dragt, A.J., van Ham, J. (Eds.), Biotechniques for Air Pollution Abatement and Odour Control Policies. Elsevier Science Publishers BV.

Nicolas, J., Romain, A.-C., Monticelli, D., Maternova, J., Andre, P., 2000. Choice of a suitable E-nose output variable for the continuous monitoring of an odour in the environment. ISOEN2000, Brighton.

Odotech, 2001. Caractérisation des émissions atmosphériques et évaluation de l'impact-odeur du lieu d'enfouissement sanitaire de la régie intermunicipale Argenteuil Deux Montagnes (Atmospheric emissions characterization and odor impact assessment of Argenteuil Deux Montagnes landfill area). Montréal, Canada, Odotech Inc.

Pagé, T., Guy, C., 1997. Odor dispersion modelling. Air and Waste Management Association's 90th Annual Meeting and Exhibition, June 813, Toronto, Canada.

Pardo, M., Sberveglieri, G., Bergonzoni, M., Ghizzoni, F., Cortellini, L., 2001. The Pico-1 electronic nose for monitoring malodors in the environment. Sardinia 2001, Cagliari, Italy.

Pasquill, F., 1974. Atmospheric Diffusion, second ed. Chichester, England.

Reinhart, D.R., Copper, D.C., Walker, B.L., 1992. Flux chamber design and operation for the measurement of municipal solid waste landfill gas emission rates. J. Air Waste Manage. Association 42, 1067-1070.

Sironi, S., Rossi, A.N., Del Rosso, R., Céntola, P., Il Grande, M., 2003. Odour impact assessment using dispersion modelling : a case study of an operating landfill. Sardinia 2003, Cagliari, Italy.

Stretch, D., Laister, G., Strachan, L., Saner, M., 2001. Odour trails from landfill sites. Sardinia 2001, Cagliari, Italy. Termonia, A.,

Termonia, M., 1999. Characterisation and on-site monitoring of odorous organic compounds in the environment of a landfill site. Int. J. Analytical Chem. 73, 43-57.

Turner, D.B., 1994. Workbook of Atmospheric Dispersion Estimates: An Introduction to Dispersion Modeling, second ed. Lewis Publishers, Inc.

Van der Auwera, L., 1991. Histograms of wind speed and statistics of Pasquill stability classes. Brussels.

Van Harreveld, A., Heeres, P., 1995. Quality control and optimization of dynamic olfactometry using $n$-butanol as a standard reference odorant. Getahrstotte- Reinhaltung der Luft 56, 55-60.

Van Langenhove, H., Van Broeck, G., 2001. Applicability of sniffing team observations : experience of field measurements. Water Sci. Technol. 44, 65-70.

VDI, 1993. VDI 3940 : Determination of odorants in ambient air by field inspections. Verein Deutscher Ingenieure, Berlin, BeuthVerlag.

Yamartino, R.J., 1984. A comparison of several "single pass" estimators of the standard deviation of wind direction. J. Clim. Appl. Meteorol. $23,1362-1366$ 